\title{
Gestão participativa \\ da arborização urbana \\ de municípios paulistas: \\ implicações, desafios e propostas
}

\author{
Danielle Paes Julião*
}

\begin{abstract}
Resumo O Programa Município VerdeAzul (MVA) interfere diretamente nos processos políticos e de gestão ambiental nos municípios do Estado de São Paulo, impulsionando avanços e/ou retrocessos em função de suas diretrizes. Neste artigo, busca-se saber em que medida o estímulo à incorporação do "princípio da gestão participativa" se materializa nos territórios e impulsiona a participação social efetiva nos processos de tomada de decisão, aprimorando os mecanismos de condução da gestão da arborização urbana. Esse artigo baseia-se em análise documental e no processo de observação participante no MVA Ciclo 2017.
\end{abstract}

Palavras-chave: gestão participativa, arborização urbana, governança, justiça ambiental.

\section{Gestion participative dans la politique de boisement urbain des municipalités de l'É-tat de São Paulo: implications, défis et pro- positions}

Resumé Le Programe "Municipio VerdeAzul" a de réelles incidences sur les politiques environnementales menées par les municipalités de l'État de São Paulo, stimulant progrès et/ou reculs. Dans cet article, nous vérifions comment l'impulsion due à l'introduction du "principe de gestion participative" se concrétise dans les territoires et favorise la démocratie participative dans la prise de décision, en améliorant les mécanismes de gestion du boisement urbain. Nous mettons en évidence des stratégies possibles permettant l'accès à l'information, la qualification de la population dans la prise de décision et l'augmentation de la conscience environnementale. II s'agit de renforcer la capacité collective de résolution des problèmes liés aux inégalités environnementales et aux conflits de gestion des espaces de nature en ville.

Mots-clefs: gestion participative, boisement urbain, gouvernance, justice environnemental.
Participatory management of urban afforestation of São Paulo municipalities: implications, challenges and proposals

\begin{abstract}
The Programme Município VerdeAzul (MVA) interferes in the political and environmental management processes in the municipalities of the State of São Paulo, driving progress and / or setbacks according to its guidelines. This article, based on documentary analysis and participatory observation process in the 2017 MVA Cycle, aims at knowing to what extent the stimulus to the incorporation of the "participatory management principle" materializes itself in the territories and promotes the effective social participation in the decision-making processes, improving the mechanisms of the urban afforestation management.
\end{abstract}

Keywords: participatory management, urban afforestation, governance, environmental justice. 


\section{Gestão participativa da arborização urbana}

Mecanismos políticos, sociais, econômicos e institucionais produzem a cidade desigual e, sistematicamente, reproduzem desequilíbrios na distribuição do percentual de cobertura arbórea entre os setores das cidades. Consequentemente, há distribuição espacial desproporcional dos benefícios ecossistêmicos, estéticos, sociais, econômicos, de segurança, saúde e bem-estar.

Essa desigualdade ambiental acentua-se na incapacidade do Estado "em controlar e fiscalizar o uso e a ocupação do solo e atuar como controlador, financiador ou provedor de moradia para as populações com menos recursos" (Grostein, 2001:15) e na existência "de diferentes opções políticas e econômicas que influenciam as configurações do espaço, quanto às condições de vida urbana [...] e às relações interclasses" (Idem) que desfavorecem a criação de espaços públicos que corroborem com a conformação de esferas públicas e novos arranjos sociais.

Para Henri Acselrad, a definição da categoria de luta por "justiça ambiental" designa um conjunto de princípios e práticas. Entre eles deve-se assegurar "que nenhum grupo social, seja ele étnico racial ou de classe, suporte uma parcela desproporcional das consequências ambientais negativas de operações econômicas, de decisões de políticas e de programas federais, estaduais, locais, assim como da ausência ou omissão de tais politicas. " (Acselrad, 2010:112).

Nesse debate, essa luta pode-se configurar na defesa dos direitos à proteção ambiental, na distribuição equitativa dos benefícios oriundos da gestão da arborização urbana, na defesa da construção de espaços com mais urbanidade e da participação plena nos processos de decisão e governança local. Ou seja, requer a compreensão de quem ganha o que e porque, e qual é o impacto da arborização urbana na qualidade de vida da cidade, nos custos da administração pública para a sua gestão e ampliação e na produção de externalidades em cada uma de suas partes.

Para a governança na gestão da arborização, nos parece evidente pensar em propostas de gestão, não como a soma de ações individuais desconectadas, mas como proposta de ação coletiva, com participação social, capaz de interferir na construção da política e extrapolar as questões administrativas de rotina e pontuais. Porém, há concepções diferenciadas para gestão participativa na arborização urbana.

* Danielle Paes Julião é Especialista Ambiental, Mestre em Ciências Ambientais (UFF), trabalha na Secretaria de Infraestrutura e Meio Ambiente do Estado de São Paulo, Brasil, ORCID <https://orcid.org/0000-0001-8265-1277>.
Na concepção de Cajado (1998, apud Lira Filho, 2003:15), a gestão participativa "pode ser compreendida como a cooperação para o plantio de árvores, ou seja, a junção de instituições governamentais, não governamentais, privadas e principalmente da população, com o objetivo de unir forças para solucionar problemas inerentes à vegetação urbana". Nesse sentido, concordamos com Lira Filho (2003:15) quando ele afirma que esse conceito é limitado, por enfatizar " a relação de poder entre as partes 
interessadas" e não cremos que essa definição permita ao poder público planejar e intervir de acordo com as demandas dos atores do território.

Já, Kuchelmeister e Braatz (1993) colocam que a participação da população na arborização urbana se dá basicamente em três níveis: "através de sua intervenção nos órgãos oficiais de planejamento, mediante contatos com grupos de ação comunitária e em negociações com o setor privado" [Tradução do autor].

Analogamente, acrescentamos a esse debate a perspectiva de participação de Danilo Gandin (2001) dentro do campo do planejamento participativo. Segundo o autor, esse campo permite integrar a dimensão social na realidade prática das entidades, incluindo a reflexão sobre às realidades sociais, a avaliação circunstanciada a partir de sua prática e a proposição de práticas alternativas para influenciar na construção social e no estabelecimento de novos valores.

Nesta obra, Danilo Gandin (2001) ressalta a perspectiva política e de divisão de poder e os divide em níveis: o $1^{\circ}$ nível é a Colaboração, no qual é permitida a participação das pessoas por meio de seu trabalho, com o seu apoio ou até com o seu silêncio, ou seja, na condição de concordância e não questionamento sobre as decisões tomadas pelo líder; o $2^{\circ}$ nível é a Decisão, o qual pode parecer ter certa democracia, mas as decisões são feitas diante de aspectos menores, desconectados e entre alternativas previamente determinadas, não afetando de fato a situação; por fim, o $3^{\circ}$ nível é a Construção em Conjunto, que ocorre quando há distribuição de poder, quando os sujeitos da ação podem opinar, propor, discordar e interferir na realidade, por meio de um trabalho coordenado, com propósitos coletivos, tornando os participantes os principais atores do processo da construção do conhecimento.

Assim, por meio de técnicas e instrumentos específicos, a participação no planejamento participativo se situa e se justifica com a "distribuição de poder, inclui possibilidade de decidir não apenas do 'como' ou do 'com que' fazer, mas também do 'o quê' e do 'para que' fazer" (Gandin,2001:88).

Sabe-se que o processo de planejamento participativo representa uma oportunidade, especialmente para os mais vulneráveis, para a compreensão de sua realidade, a geração de alternativas coletivas para a solução dos problemas e atuação organizada. No entanto, os mecanismos participativos pela heterogeneidade dos sujeitos, pelo cenário político nacional composto por perda de confiança nas instituições políticas, crise econômica, crescimento da pobreza e da exclusão social fragilizam a participação social e impedem o exercício da cidadania. Outro fator impeditivo é o desconhecimento da população sobre os seus direitos e sobre os mecanismos e estratégias que possam implicar em respostas ou soluções para seus problemas e na superação das relações de poder consolidadas.

Destaca-se aqui a necessidade de fortalecimento de uma educação em que a problemática ambiental está intrinsecamente relacionada aos problemas sociais e intenciona a superação da injustiça ambiental, por meio da pedagogia do conflito (Layrargues, 2012), a essa abordagem chamamos de Educação Ambiental (EA) crítica.

Portanto, o entendimento de EA com foco na gestão participativa da arborização urbana fundamenta-se aqui em três conceitos: gestão participativa, como participação social 
para a tomada de decisão e mediação de conflitos no âmbito da gestão ambiental pública (Brasil, 2018); conflitos socioambientais, como resultado da divergência de interesses sobre a apropriação material ou cultural, a partir do impedimento do uso dos recursos ou do resultado de atos inapropriados, que interferem nos interesses de, pelo menos, uma das partes (Quintas, 2004); educação ambiental crítica, entendida por processos educativos não formais, eminentemente políticos, intencionais e emancipatórios, que buscam explicitar conflitos, mediar interesses divergentes e qualificar para a participação ativa dos cidadãos, em desigual situação de poder, nos espaços de governança e decisão existentes (Idem, 2004).

Partindo destes pressupostos teóricos, esse estudo propõe uma apresentação do Programa Município VerdeAzul (MVA) e ressalta a sua interferência nos processos políticos e de gestão ambiental nos municípios do Estado de São Paulo. Em seguida, nos debruçamos na leitura quantitativa duma das 10 Diretivas do MVA, a Diretiva de Arborização Urbana e na leitura qualitativa da tarefa: "Ação de Educação Ambiental com foco na 'gestão participativa da Política Municipal de Arborização Urbana'", para iniciarmos a discussão que tem como centralidade entender em que medida o estímulo à incorporação do "princípio da gestão participativa" se expressou nas propostas dos municípios durante o Ciclo MVA 2017 e impulsionou a participação social efetiva nos processos de tomada de decisão e gestão dos conflitos ambientais ocasionados por essa política.

\section{O Programa Município VerdeAzul e a Diretiva de Arborização Urbana}

O Programa Município VerdeAzul, criado em 2007, interfere diretamente nos processos políticos e de gestão ambiental municipal, podendo proporcionar avanços e/ou retrocessos em função de suas diretrizes. Na última década, essa política passou por reestruturações técnicas e conceituais. Atualmente, estrutura-se em um conjunto de "tarefas", distribuídas em 10 diretivas, entre elas está a Diretiva de Arborização Urbana.

Essas tarefas expressam a priorização da agenda ambiental municipal no Estado de São Paulo e traz entre os motivos que justificam a existência de uma Diretiva específica para a Arborização Urbana, a constatação de que a maior parcela dos municípios paulistas ainda se encontra em estágio inicial de construção e fortalecimento dessa política, normalmente, subjugada a outros setores e com baixa regulamentação municipal e federal.

Esse fato é reafirmado na avaliação dos resultados do Ciclo MVA 2017, no qual dos 645 municípios do Estado de SP, 207 (32,09\%) dos municípios informaram ter o Plano Municipal de Arborização e destes apenas 134 (20,76\%) dos planos contém proposta de cronograma para a execução das ações e em poucos casos, relata-se dotação orçamentária específica para implantação. Dados que nos demonstram a fragilidade ou inexistência do instrumento de planejamento e gestão na maior parte dos municípios paulistas.

Acrescenta-se aos desafios desta política, um discurso de rejeição da população à arborização urbana. Essa percepção negativa da sociedade quanto à presença das árvores se revela e se constrói na materialidade concreta de sua experiência cotidiana. 
A rejeição é fruto dos conflitos da gestão da arborização urbana: incompatibilidade do projeto de habitação com a proposta de arborização, espaçamento diminuto no calçamento para o desenvolvimento das espécies arbóreas, insuficientes estratégias para reduzir a desigualdade no percentual de projeção de copa entre bairros, incapacidade de resposta do poder público em relação às demandas de poda, incompatibilidade da rede de fornecimento de energia elétrica com a vegetação, baixa disponibilidade dos atores sociais para negociar com essas instituições, entre outros motivos.

A constatação da vulnerabilidade de implementação da política de Arborização Urbana, se deve também a necessidade de exigência de aspectos básicos para a consolidação dessa política, tais como: apresentação do senso arbóreo e diagnóstico situacional, cálculo percentual da projeção de copa das árvores, capacitação profissional e produção de material informativo sobre a política municipal.

Intencionando uma ambiência favorável à governança ambiental democrática e mais urbanidade nas cidades, foram propostas duas novas "tarefas" para essa Diretiva, a partir do ano de 2017 e institucionalizadas na Resolução SMA 33/2018 (Brasil, 2018). Entre elas:

(i) "Ação VerdeAzul de Educação Ambiental com foco na 'gestão participativa da política de arborização urbana', que se caracteriza como uma ação processual, permanente e contínua de informação e formação, crítica e contextualizada, que intenciona estimular a cultura política, qualificada e ativa, em diferentes cenários, em esferas de representação direta ou indireta, coletivas ou individuais ".

Não se intenciona a transformação da realidade de uma cidade apenas com processos educativos, mas entendemos que o cumprimento da tarefa, mesmo inicialmente limitada no espaço de uma rua ou bairro, poderá fortalecer, ao longo do tempo, uma cultura cívica da participação, aspecto basal da governança ambiental democrática entendida por:

"arranjos institucionais que regulam a relação entre governo e sociedade, formados por um conjunto de normas, valores, agentes coletivos e individuais que buscam a resolução de conflitos ambientais de forma participativa, tanto no que concerne à ação coletiva dos diferentes atores sociais, como nas ações de planejamento, fiscalização, regulação do uso dos recursos naturais e do espaço público, da mesma forma nos processos que envolvem a gestão dos conflitos ambientais". (Julião, 2008:15)

Nesse conceito, se insere a dimensão da inclusão social na perspectiva do enfrentamento da desigualdade para o exercício efetivo dos direitos de cidadania e a dimensão da diversidade pela necessidade de reconhecimento da multiplicidade de interesses e de mecanismos capazes de atender às mais variadas demandas.

\section{A análise das propostas - Ação VerdeAzul com foco em gestão participativa}

Nesta análise, consideraremos o conceito de gestão participativa, entendida aqui como participação social na tomada de decisão e mediação de conflitos, estruturados em um conjunto de processos dialógicos que intencionam compartilhar conhecimento, 
identificar demandas, planejar ações e tomar decisões coletivamente. Nesse contexto, tal como o entendimento de Gandin (2001), os processos participativos devem integrar a dimensão social na realidade prática e viabilizar meios para a sua intervenção na realidade estrutural injusta da sociedade. Como um dos meios para se alcançar esse fim, defendemos aqui o desenvolvimento de processos formativos dentro da perspectiva da educação ambiental crítica e da pedagogia do conflito, tal como apresentadas por Quintas (2004) e Layrargues (2012).

Para melhor compreender os aspectos políticos e de divisão de poder das Ações VerdeAzul de Educação Ambiental com foco em "Gestão Participativa" da Diretiva de Arborização Urbana submetidos ao MVA, classificaremos as ações municipais de acordo com os níveis de participação de Gandin (2001) citados anteriormente.

Dos 384 municípios paulistas que enviaram o projeto ambiental ao final do Ciclo MVA 2017, menos de 1/3 ou 124 municípios se propuseram a enviar o relatório "comprovando" a realização de ocorrência de "gestão participativa". Dentre estes, 54 ações preencheram itens considerados mínimos para pontuar o ritmo da Ação VerdeAzul composta por: diagnóstico, proposta, ferramenta de comunicação ambiental, execução e comprovação de resultados quantitativos e qualitativos.

Para análise qualitativa, foram escolhidos 38 municípios ou 10\% do total de projetos entregues. Utilizamos como critério para eleição e avaliação qualitativa, ser da Região Metropolitana de Campinas (RMC) ou estar entre os primeiros lugares do Ranking Estadual, o que, em tese, são os melhores projetos do Estado de São Paulo. Dois municípios da RMC não participaram nesse ano e foram substituídos por outros dois, na sequência do Ranking MVA 2017.

Esse recorte nos permitiu avaliar 37\% (20) dos municípios que pontuaram em sua totalidade na tarefa em questão, de acordo com os avaliadores do MVA e 18 que pontuaram parcialmente ou não receberam nenhuma pontuação. Essa estratégia também nos permitiu uma análise em relação aos relatórios enviados, mas que foram considerados inadequados pelos técnicos do MVA.

Dessa análise, identificamos que 57,9\% (22) das propostas enviadas para comprovação de realização da "Ação de EA na Gestão Participativa, na Política de Arborização Urbana" enquadram-se na categoria "Colaboração", com a realização de plantio coletivo direcionado pelo poder público, plantio coletivo por demanda da sociedade, plantio por demanda individual, estimulado por ações de doação pública de mudas, por levantamento de interesse porta a porta ou por canais de comunicação estimulados pela prefeitura, para escolha das espécies de árvores de "interesse do cidadão" a serem plantadas futuramente pela prefeitura.

Em grande parte dos casos, as ações caem no senso comum da EA conservadora, que reproduz práticas e atividades pontuais, pautadas na valorização da agenda verde, em questões ecológicas e no contato com a natureza a fim de "sensibilizar" os sujeitos pelo amor e respeito à natureza. Práticas totalmente distanciadas das dinâmicas sociais e políticas e de seus respectivos conflitos. Nesses casos, não se aspira questionar a estrutura social vigente e os paradigmas dominantes, muito menos realizar a gestão participativa de uma política pública. 
Apenas 22,7\% (5) dos 22 projetos de plantio se dispuseram a realizar alguma espécie de reunião ou diálogo com associação de bairros ou organizações da sociedade civil. Desses, dois projetos partem da identificação de um bairro com baixo índice arbóreo ou um problema ambiental, se aproximam da associação de bairro para ganhar o seu apoio, com o intuito de convencê-los a realizar o plantio direto, ou para solicitar à associação a identificação de residentes interessados em plantar mudas na fachada de seu imóvel. Nesses casos, também não ocorre o planejamento conjunto da ação, permitindo-nos enquadrá-los no nível de "Decisão", com aparente delegação de poder e baixo nível de tomada de decisão.

Um dos municípios participantes relatou uma Ação que sugere possível imposição do poder econômico sobre os interesses coletivos ao revelar uma participação manipulada em que "dá-se o direito" de escolha aos cidadãos, de bairros com baixo percentual de projeção de copa, em detrimento da "compensação ambiental", por supressão arbórea, em bairros distintos.

Nos casos das companhias elétricas e telefônicas, o poder público municipal e as instituições participantes das esferas públicas de representação democrática tendem a aceitar a poda drástica ou a substituição de árvores maduras e de grande porte por outras que atendam aos interesses econômicos das concessionárias fornecedoras de energia, com diminuição do custo de manutenção de poda obrigatória e do custo de manutenção da rede elétrica. Entretanto, "empresas de energia elétrica costumam cortar árvores de maneiras que nem sempre equilibram com sucesso as metas de incentivar a saúde das árvores e as metas de redução da interferência nas linhas de energia. [Tradução do autor]" (McDonald, 2017:10).

Logo, projetos de substituição de árvores ofertados por concessionárias de energia devem ser vistos com cautela. Pois, imbuídos de critérios exclusivamente econômicos, ausentes de preceitos de justiça ambiental, poderão ocasionar a redução dos custos das empresas, a redução do volume de reclamações por rompimento de energia e até a redução a curto do prazo dos custos da municipalidade com a gestão da arborização urbana. Mas poderão afetar a médio e longo prazo na estrutura dos serviços ecossistêmicos associados a floreta urbana com redução da qualidade de vida e da qualidade ambiental (Nicodemo, 2009:10).

Outros 13,2\% (5) realizaram somente ações informativas com propostas de realização de palestras e envolvimento ora da população, ora de agentes municipais e podadores, e, em um dos casos, foi realizada exposição dialogada com vereadores, intencionando diminuir a pressão dos mesmos sobre os profissionais para a realização de poda e supressão de árvores sem o respaldo técnico.

Porém, o município em questão se propõe apenas a realizar uma ação de informação sobre a gestão da arborização, sem destacar se haverá um processo de debate e deliberação em outras esferas públicas, que possam implicar no delineamento de limites, multas ou normativas que imponham ações ou restrições às concessionárias ou mesmo preservem o trabalho técnico dos agentes municipais e garantam o cumprimento das diretrizes do Plano Municipal de Arborização Urbana.

Situação que reforça a pressão institucional de concessionárias de serviços públicos aos agentes públicos e o desconhecimento potencial dos tomadores de decisão do 
"valor multifacetado das árvores de rua para a sociedade", incluindo o seu valor para a saúde da população (McDonald, 2017:9).

Essas ações se aproximam ao entendimento da gestão participativa da arborização urbana de Cajado (1998, apud Lira Filho, 2003) e se afastam do conceito de EA Crítica, na Gestão Ambiental Pública. Possivelmente, limitadas e condicionadas pelas questões técnicas, operacionais, administrativas e conceituais daqueles que as propõem. Cabe dizer que não é possível inferir se as questões políticas e institucionais também determinaram a superficialidade da proposta.

Apenas $21 \%$ (8) das propostas analisadas se aproximam da ideia conceitual de valorização ou criação de esferas públicas para gestão participativa da arborização urbana. Entretanto, em nenhuma delas pode-se perceber a configuração da proposta de ação de EA dentro do "princípio da gestão participativa". Apenas uma proposta considerou a participação social em esfera pública de representação democrática.

Dois municípios relataram a realização de fóruns de discussão com a exposição da temática e tomada de algumas sugestões para a melhoria da gestão. Um município que possui o licenciamento municipalizado relata que os conselheiros opinam nos processos de supressão e compensação de vegetação arbórea. Ainda que o ato seja relevante, pois esses processos fortalecem essa esfera pública de participação social representativa, delegando o poder no processo de gestão. A experiência não evolui do aspecto estritamente técnico, da análise de empreendimentos para o debate ambiental com estratégias para a operação política a favor do enfrentamento de conflitos e problemas ambientais inerentes à arborização urbana.

Outros dois municípios relataram a realização de Audiências Públicas, mas causam ambiguidade quanto a sua relevância e significado para a gestão participativa e para o fortalecimento da governança ambiental democrática; seja pela generalidade da temática proposta, seja pelas fragilidades do relatório, que nos põe em dúvida quanto ao cumprimento de dispositivos legais que instituem e normatizam as Audiências Públicas.

As Audiências Públicas, em geral, são ações pontuais utilizadas nos processos decisórios de diferentes políticas e seus princípios e objetivos estão descritos em uma diversidade de atos normativos. Entre eles, a garantia da divulgação ampla e prévia do documento convocatório, especificando seu objeto, metodologia e o momento de realização; livre acesso aos sujeitos afetados e interessados; sistematização das contribuições recebidas; publicidade, com ampla divulgação de seus resultados; disponibilização do conteúdo dos debates; compromisso de resposta às propostas recebidas; pluralidade e diversidade de participantes; garantia de plena participação social etc (Brasil, 2014).

A confusão entre os mecanismos de participação social pode ocasionar desconfiança na população sobre a efetividade institucional da Audiência Pública para mediação de conflitos e como expressão do compromisso político em relação às deliberações populares.

Ressaltamos que a Audiência Pública em si não se caracteriza como um processo de EA crítica. É no preparo antecipado dos interessados, com intenção de esclarecer as 
questões sobre o objeto de disputa e interesse, que ela se configura decisiva para que haja uma participação efetiva da sociedade e determinante para a participação plena de grupos vulneráveis.

Em um dos casos, a ata da audiência revela que certo participante suscita a possibilidade de plantio de árvores frutíferas na cidade e a proposta é tecnicamente refutada. Ainda que o município possua direito sobre o ordenamento de uso e ocupação do solo, exista possível legislação municipal que impeça o plantio de frutíferas na zona urbana e a rejeição técnica se justifique pela imputação de responsabilidade à prefeitura na ocorrência de incidentes, a atitude do gestor municipal nos faz questionar se é inviabilidade técnica ou indisponibilidade política para a investigação da viabilidade da ampliação da funcionalidade do uso do solo urbano.

Essa situação também nos faz refletir sobre a ocorrência de possível arbitrariedade do processo, se houve efetiva participação social e se há desconexão ou desconhecimento de ideias vanguardistas, como o PRO-FRUTI, que instituiu o Programa Nacional de Arborização Urbana com Árvores Frutíferas (Brasil, 1986) e/ou de políticas públicas reconhecidas, como o da Cidade de Montreal, no Canadá, que integram a promoção da agricultura urbana com árvores frutíferas à expansão e ao incremento da arborização urbana, à gestão coletiva e voluntária da população, aos objetivos de desenvolvimento sustentável e às recomendações da Organização das Nações Unidas para a Alimentação e a Agricultura.

A seguir, apresentamos três propostas que se mostram bem próximas ao conceito central dessa discussão, embora equivocadamente não pontuadas por técnicos do MVA. O primeiro projeto se configura na atuação ativa e conjunta de uma organização civil com a prefeitura, no plantio de centenas de árvores no centro da cidade, para minimizar as ilhas de calor que se formam no município. De acordo com o relatório da Ação, ela se sustenta na participação voluntária de cidadãos, de instituições e de empresas privadas que realizam a doação de recursos para a compra e transporte das mudas, acompanhamento de técnicos municipais e ferramentas de comunicação ambiental.

Para esclarecer a população sobre as razões e a importância do projeto foram relatadas a realização de campanhas de comunicação social, como as pessoas poderiam ser voluntárias e a responsabilidade de cada uma das partes envolvidas. A proposta de sensibilização e mobilização social resulta na continuidade do projeto, ultrapassando os ciclos das gestões municipais, pois ele tem seu início em 2016. Talvez, pelo fato da tarefa de gestão participativa na arborização urbana ter sido inserida na Diretiva, a ação foi impulsionada. Todavia, percebe-se pouco envolvimento da prefeitura no planejamento e orientação técnica do processo.

Realçamos que campanhas de comunicação social colaboram para a formação de um discurso coletivo favorável à arborização urbana. Orquestradas com estratégias formativas que aprofundem o tema e contrastem as realidades, essas ações comunicativas poderiam facilitar a atribuição de valor às situações ambientais pelos cidadãos e impulsioná-los para a realização coletiva da transformação da realidade. Porém, seria ingênuo acreditar que apenas a tomada de consciência coletiva possibilitaria o apaziguamento e a resolução dos conflitos ambientais, pois nem todo aquele que é 
desperto encontra condições favoráveis para a transformação do seu território, tão pouco uma mudança estrutural.

O segundo projeto partiu da identificação de espécies invasoras em determinados bairros e realização do Plano de Manejo Sustentável de Espécies Invasoras. Após a realização de ações para esclarecimento técnico e administrativo da proposta de supressão das espécies de Leucenas $s p$ aos moradores do bairro foram coletadas sugestões da população para a compensação das árvores suprimidas. Nesse processo, relata-se envolvimento de 70 pessoas. Finalizado a consulta pública, ressalta-se a continuidade do envolvimento da população na indicação de árvores invasoras restantes em outras áreas do bairro. Segundo relato, a ação aproximou a prefeitura da Associação de Moradores, que solicitou mais outro plantio no bairro e reduziu possível conflito entre os moradores e a prefeitura. Situação que, provavelmente, se realizada de forma arbitrária e autoritária, geraria grande insatisfação social e estranhamento nas relações político-institucionais entre as partes interessadas, como já pôde ser observado em leitura de relatório de outro município localizado no litoral paulista.

Por último, outro município relata uma política de urbanismo denominado Projeto "Entre a casa e a escola", que se propõe a requalificar o espaço urbano a partir da escuta e coleta de sugestões da população, com participação da comunidade escolar e da rede de assistência social. A ação iniciou com o traçado e diagnóstico do caminho para três escolas e eleição de uma delas para projeto piloto. Foi realizada a apresentação do projeto, por meio de palestras aos alunos da escola e no projeto "Reunião de Rede", que tem por objetivo reunir, uma vez por mês, membros da comunidade, associações de bairro, diretoras de escola e assistentes sociais, para discussão de propostas e divulgação de iniciativas para a comunidade. Foram coletadas sugestões para a readequação do projeto por meio de questionários aplicados e debate.

Esses dois últimos projetos, ainda que incipientes enquanto definidores de uma gestão participativa de uma política pública possuem grande proximidade com as características do nível de participação "Construção em Conjunto". Revelam a existência de processos formativos baseados na identificação de um problema ambiental; discussão do processo de intervenção com a comunidade diretamente afetada; criação de mecanismo de participação social, debate, tomada de decisão e reformulação do projeto técnico inicial.

Particularmente, o último projeto se constrói com a participação de população em situação de vulnerabilidade social e ambiental. Objetiva a melhoria da qualidade de vida das comunidades, fortalece outras esferas públicas consolidadas, que servem de aproximação entre o poder público e a comunidade, oportuniza a integração da proposta a outras políticas públicas de desenvolvimento social e assistência do bairro. Para fortalecimento da proposta de participação e envolvimento social, esse projeto poderia incluir a dimensão de geração de emprego e renda com a capacitação da comunidade em técnicas de silvicultura e agricultura urbana ou outras ações que incluam a perspectiva econômica de forma direta, delineando o projeto dentro do tripé da sustentabilidade. A mesma ideia-chave que a árvore, a arborização urbana e a floresta urbana carregam em si.

Contudo, nos três casos, os projetos dialogam no nível da esfera pública de participação direta do cidadão e na escala do bairro e não deixam claro se haverá a oportunidade 
para uma autocrítica e reflexão do projeto; e esclarecimento e harmonização dos interesses do poder público e da comunidade. Não é possível inferir se a intervenção poderá repercutir, de fato, na melhoria das condições de vida daquelas populações ou na integração e maximização dos benefícios ecológicos, econômicos e ambientais associados à arborização urbana.

\section{Discussões finais}

As propostas municipais ratificaram a frágil cultura cívica de participação e de gestão participativa nas políticas ambientais urbanas nos municípios paulistas, em especial, na Política Municipal de Arborização Urbana. Na maior parte dos casos analisados, as propostas não expressam uma ambiência favorável para o desenvolvimento de uma política que considere o princípio da participação democrática nas esferas representativas ou nas esferas de participação direta do cidadão nas diferentes etapas dos processos de planejamento e gestão. Não se observou como finalidade para a Ação a redução da injustiça ambiental e da distribuição desigual dos benefícios da arborização urbana, das estruturas verdes pelos diferentes setores da cidade, ainda que alertados para essa necessidade em uma das tarefas técnicas da Diretiva.

Quanto ao estímulo à incorporação do "princípio da gestão participativa" por meio da Ação VerdeAzul de Educação Ambiental proposto no Ciclo MVA 2017, ele se expressou de maneira tímida nas propostas dos municípios, mas considera-se que foi aberta uma janela de oportunidade para aqueles municípios que almejem a construção de uma ambiência mais favorável à participação social nos processos de tomada de decisão e gestão de conflitos da política de arborização urbana.

Na maior parte dos casos, as propostas de EA se restringiram a participação passiva, no nível de "Colaboração", alguns casos no nível de "Decisão" e raramente no nível "Construção em Conjunto" (Gandin, 2001). Frequentemente, o acesso à informação se deu de modo superficial e descontextualizado, intencionando, principalmente, "educar" e mobilizar para ação com o propósito de reduzir os custos para os cofres públicos e garantir prestígio político para a gestão ou instituição realizadora.

Observa-se que as propostas trafegam numa escala de intencionalidade, incluindo aspirações que assumem que determinados níveis de desigualdade e questões estruturais não serão modificadas, exigindo estratégias que amenizem injustiças socioambientais, até a intenção velada que legitima os mecanismos de opressão e reforçam, em muitos casos, que o discurso da participação só serve para manipulação das pessoas e como "simulacro de participação" (Gandin, 2001).

Ou seja, mesmo com o incentivo do Estado, é urgente a formação dos agentes públicos municipais para que as propostas de Ação de EA intentem a qualificação para a participação, seja nas esferas públicas de democracia representativa ou para a criação de mecanismos que impulsionem a participação direta do cidadão.

Entende-se que a elaboração de uma proposta de Ação de EA, considerando as concepções aqui indicadas, deve ser antecedida pela decisão política e administrativa para o fomento de uma cultura cívica da participação dentro da gestão pública, da clara compreensão dos agentes municipais (indutores do processo) sobre qual tipo de 
intervenção na realidade será proposta em conjunto com os sujeitos participantes e qual o conceito de gestão participativa da arborização se baseará, buscando sempre que possível equilíbrio entre as participações diretas e representativas.

Porém, em muitos municípios, a legitimidade e a representatividade das instâncias de governança são frágeis e há dificuldades estruturais, tanto para a construção de uma agenda comum entre os conselheiros de políticas públicas e o poder público, quanto para o engajamento social, o que torna a proposição da Ação VerdeAzul de EA com foco na "gestão participativa" da arborização urbana uma tarefa ainda mais complexa. Contudo, a insistência no desenvolvimento de ações de EA apenas dentro dos dois primeiros níveis de participação de Gandin (2001), pode bloquear ou retardar o desencadeamento do processo educativo derivado da reflexão comunitária necessária para a governança inclusiva e democrática.

Uma vez que a gestão municipal, normalmente, centra os seus esforços no manejo e proteção do indivíduo arbóreo, negligenciando o ambiente comunitário que vivifica a floresta urbana e suas relações com as outras políticas, podemos depreender que são elementos centrais na discussão da viabilidade institucional e política da gestão participativa da arborização urbana o estabelecimento e o fortalecimento de esferas e arranjos institucionais favoráveis à participação de diferentes atores coexistentes no território; o compartilhamento de conhecimentos e informações entre as partes interessadas na gestão; a definição de mecanismos legais e administrativos, que favoreçam a governança político-estratégica entre todos os setores da gestão pública municipal, com metas, objetivos comuns e definição de recursos para a sustentação e expansão da floresta urbana.

Esse entendimento requer a existência de uma política pública que ultrapasse a visão restrita da gestão de espécies arbóreas situadas apenas em vias, logradouros e praças; alcance o planejamento das múltiplas relações entre o ambiente construído, a natureza e os mecanismos de transformação do espaço urbano e atenda aos princípios fundamentais para a sustentabilidade das cidades, tais como: distribuição equitativa de recursos e benefícios, justiça ambiental e democracia.

Por fim, mesmo que haja lacunas, podemos entender que a incorporação do "princípio da gestão participativa" pelo MVA projeta um cenário mais positivo e propositivo para a melhoria da qualidade ambiental e de vida da população, contribuindo para uma ambiência mais favorável à consolidação da governança ambiental democrática.

\section{Referências bibliográficas}

- ACSERALD, H., 2010. Ambientalização das lutas sociais - o caso do movimento por justiça ambiental. Estudos Avançados, São Paulo, 24(68), 103-119.

- BRASIL, 1986. Lei Federal n 7.563, de 19 de dezembro de 1986, institui o PRÓ-FRUTI Programa Nacional de Arborização Urbana com Árvores Frutíferas e determina outras providências. Legislação Federal.

- BRASIL, 2014. Decreto Federal n 8.243, de 23 de maio de 2014, institui a Política Nacional de Participação Social - PNPS e o Sistema Nacional de Participação Social - SNPS, e dá outras providências. Legislação Federal. 
- BRASIL, 2018. Resolução SMA n 33, de 28 de março de 2018, estabelece procedimentos operacionais e os parâmetros de avaliação da Qualificação para a Certificação e Certificação no âmbito do Programa Município VerdeAzul. Secretaria de Estado do Meio Ambiente, Governo do Estado de São Paulo, 38p. Resolução Estadual.

- GANDIN, D., 2001. A Posição do Planejamento Participativo entre as ferramentas de intervenção na realidade. Revista Currículo Sem Fronteiras, 01(01), 81-95.

- GROSTEIN, M. D., 2001. Metrópole e expansão urbana: a persistência de processos insustentáveis. São Paulo em Perspectiva, 15(1), 13-19.

- JULIÃO, D. P., 2008. Turismo e Governança Ambiental Democrática: reflexões em torno do Plano de Manejo e da visitação pública na APA de Guapi-Mirim (RJ) / Danielle Paes Julião. - Niterói: [s.n.], 2008. 184f. Dissertação de Mestrado (Mestrado em Ciência Ambiental) Universidade Federal Fluminense, 2008.

- KUCHELMEISTER, G. \& S. Braatz,1993. Una nueva visión de la silvicultura. [on line] In: Revista internacional de silvicultura e industrias forestales, Unasylva, FAO, 173/44, pp.13-18. Available from <http://www.fao.org/docrep/u9300s/u9300s00.htm>. Access on 12 february 2018.

- LAYRARGUES, P. P., 2012. Para onde vai à educação ambiental? O cenário político-ideológico da educação ambiental brasileira e os desafios de uma agenda política crítica contra-hegemônica. Revista Contemporânea de Educação, 7/14, pp.388-411.

- LIRA FILHO, J. A., 2003. Arborização participativa: implicações na qualidade das florestas urbanas. Viçosa: UFV. Tese (Doutorado em Ciência Florestal) - Universidade Federal de Viçosa, 104p.

- McDONALD, R. et al., 2017. Funding Trees for Health: An Analysis of Finance and Policy Actions to Enable Tree Planting for Public Health. USA, The Nature Conservancy. 40p.

- NICODERMO, M. L. F., 2009. Por que manter árvores na área urbana? Recurso eletrônico / Maria Luiza Franceschi Nicodemo, Odo Primavesi — Dados eletrônicos. São Carlos: Embrapa Pecuária Sudeste. 41 p.

- QUINTAS, J.S., 2004. Educação no processo de gestão ambiental: uma proposta de educação ambiental transformadora e emancipatória. Brasília: Ibama.19p. 